\title{
Factors influencing nurses' job satisfaction in selected private hospitals in England
}

\author{
RP Lephalala, MA Cur student, \\ Department of Health Studies, University of South Africa \\ VJ Ehlers, D Litt et Phil, \\ Professor, Department of Health Studies, University of South Africa \\ MJ Oosthuizen, D Litt et Phil, \\ Senior lecturer, Department of Health Studies, University of South Africa
}

Keywords:

Herzberg's Theory of Motivation, nurses' job satisfaction, retention of nurses.

\section{Abstract: Curationis 31(3): 60-69}

The quantitative descriptive survey used self-completion questionnaires to study factors influencing nurses' job satisfaction in selected private hospitals in England. Herzberg's Theory of Motivation was used to contextualise the results obtained from 85 completed questionnaires.

In terms of Herzberg's Theory of Motivation, the most important extrinsic (hygiene) factor was no satisfaction with their salaries compared to nurses' salaries in other private hospitals in England, in the NHS and even at their own hospitals. However, most nurses were satisfied with the other extrinsic factors (organisation and administration policies, supervision and interpersonal relations). The most important intrinsic factors (motivators), influencing nurses' job satisfaction was their lack of satisfaction with promotions (including the fact that their qualifications were reportedly not considered for promotions), lack of advancement opportunities and being in deadend jobs, and lack of involvement in decision- and policy-making activities.

Nurses' levels of job satisfaction might be enhanced if promotion policies could be consistent, advancement opportunities implemented, qualifications considered for promotions, salary issues clarified, and if nurses could be involved in decision- and policy-making. Enhanced levels of job satisfaction could help to reduce turnover rates among registered nurses at the private hospitals in England that participated in this study.

\section{Introduction}

Job satisfaction is an essential element for the maintenance of the workforce of any organisation. Lack of job satisfaction for employees not only leads to high turnover rates but could also have detrimental effects on the individual, like burnout (Mrayyan, 2005:42). Although turnover provides the organisation with new ideas and is a normal process, a high turnover rate leads to the inability of an organisation to provide quality care, raises personnel recruitment, selection and orientation costs, and lowers employees' job satisfaction levels (Marquis \& Huston, 2003:235). The United Kingdom (UK) imports large number of nurses annually. Unless the UK's nurses experience job satisfaction, they are likely to have high turnover rates, reducing the value added to the UK's health services by these recruitment efforts and costs. 


\section{Background information about the United Kingdom's health and nursing services}

According to the 2003 census (British Population Statistics, 2003), England is one of the most densely populated countries in the world. Nearly $84 \%$ of the total population of the UK lives in England. The total population in the UK was approximately 59,5 million in June 2003 and England had about 49.3 million people. Projections based on the 2002 midyear statistics, suggest that England's population will continue to increase. This could lead to increased demands for England's health care services to enhance its nurses' levels of job satisfaction in order to retain them. Nurses satisfied with their jobs are less likely to resign from their current positions than those who are not satisfied. Thus enhancing nurses' job satisfaction, should decrease nurses' turnover rates.

In the late 1990s, the United Kingdom's (UK) National Health Service (NHS) stated that it needed to increase its number of nurses with 20000 by 2004 in order to supply the required level of health services to the UK's citizens (Buchan, 2007:1322). This target was easily achieved by training increased numbers of nurses, and by recruiting nurses internationally (by both the NHS and the UK's private health care sector). Reportedly 16155 internationally recruited nurses joined the UK register while 14538 did so from Britain's nurse education programmes during 2002 (Aiken, Buchan, Sochalski, Nichols \& Powell, 2004:75). As many as 40-50\% of the UK's newly registered nurses come from foreign countries (Buchan, $2007: 1321 ; 1323)$ and there are approximately 670000 nurses and midwives on the UK's professional register. During 2004/5 a total of 8044 verifications of qualifications (Buchan, 2007:1329) were requested from the Nursing and Midwifery Council (NMC), indicating that these nurses might apply for registration in other countries and leave the UK. Although the UK loses nurses to English-speaking countries, such as Australia, Canada and the United States of America (USA), the UK "...remains a net importer of nurses" (Buchan, 2007:1321). The internationally recruited nurses supply the numbers required without investing UK time and

Table 1 Summary of Herzberg's theoretical constructs

\begin{tabular}{|l|l|}
\hline $\begin{array}{l}\text { Intrinsic (motivating) factors } \\
\text { focussing on job satisfaction }\end{array}$ & $\begin{array}{l}\text { Extrinsic (hygiene) factors focussing } \\
\text { on no job satisfaction }\end{array}$ \\
\hline Achievements & $\begin{array}{l}\text { Working conditions } \\
\text { Recognition }\end{array}$ \\
$\begin{array}{l}\text { Salary } \\
\text { Organisation/administration policies } \\
\text { The nature of work itself }\end{array}$ & $\begin{array}{l}\text { Supervision } \\
\text { Advancement (promotions) }\end{array}$ \\
\end{tabular}

money into these nurses' training. However, research is required about the job satisfaction and retention levels of nurses working in the UK, because there is a causal relationship (Cowin, 2002:284) between nurses' retention and job satisfaction. According to Aiken (2007:1315) retention of nurses is important because shortages of nurses could lead to work overload, burnout and a lack of job satisfaction among the remaining nurses, increasing the likelihood of even greater turnover rates, potentially compromising standards of nursing care. Kingma (2007:1294) warns: "Injecting migrant nurses into dysfunctional health systems - ones that are not capable of attracting and retaining staff domestically - is not likely to meet the growing health needs of national populations",

\section{Problem Statement}

Intrinsic (motivating) and extrinsic (hygiene) factors influence nurses' job satisfaction, and by implication their turnover rates. The participating private group of hospitals in the UK needed to identify factors influencing nurses' job satisfaction, to reduce their nurse turnover rates, enhance the quality of nursing care rendered to their patients, and to save recruitment, selection and orientation costs.

\section{Conceptual Framework}

Herzberg's Theory of Motivation was used as the theoretical framework for this study. This theory postulates that intrinsic and extrinsic factors enable individuals to satisfy their personal needs and experience job satisfaction in a work environment (Ball, 2003). Herzberg's Theory of Motivation postulates that the phenomenon of job satisfaction and/or no satisfaction, is the function of two need systems, namely, extrinsic or hygiene and intrinsic or motivation factors factors. These two groups of factors enable employees to avoid unpleasant situations and discomfort and to meet their personal development needs (Ball, 2003). (In terms of Herzberg's theory the term "no satisfaction" is used, not dissatisfaction, because the lack of satisfaction is implied, not the state of being "dissatisfied"). Table 1 summarises the most important intrinsic and extrinsic factors, in terms of Herzberg's theory's constructs, addressed by this study as influencing nurses' job satisfaction, and by implication their turnover rates.

According to Daft (2000:540), Herzberg maintains that an individual's attitudes to work can determine his/her successes or failures in fulfilling specific roles. Herzberg studied "what do people want from their jobs?" He asked people to explain situations where they felt good or bad in relation to their jobs. These results were categorised as extrinsic and intrinsic factors related to job satisfaction. Extrinsic (hygiene) factors relate to no job satisfaction including supervision, company policy and administration, working conditions and interpersonal relations. Poor hygiene factors increase employees' levels of no satisfaction. However, good hygiene factors do not improve job satisfaction but simply reduces levels of no job satisfaction.

Intrinsic factors (motivators) include achievements, recognition, work itself, advancement, responsibility and growth. These factors influence job satisfaction. Without motivators, employees become neutral towards their jobs. The presence of motivators increases the job satisfaction levels. Therefore intrinsic factors (motivators) focus on job satisfaction and extrinsic (hygiene) factors focus on no job satisfaction factors. Herzberg's theory's constructs indicate that once the hygiene factors are properly addressed, the motivators will promote job satisfaction and productivity. 


\section{Definitions of concepts}

Job satisfaction is the extent to which the employee enjoys the job. Nurses' levels of job satisfaction could influence nurse turnover rates (Mrayyan, 2005:41). In this study job satisfaction refers to individual nurses' feelings about their jobs as meeting their needs. Nurses' levels of job satisfaction are influenced by extrinsic (hygiene) and intrinsic (motivating) factors.

Factors imply "any circumstances that contribute towards a result" (Webster's Concise Edition Dictionary and Thesaurus, 2002:118). In this article factors refer to circumstances which may influence nurses' decisions to leave the services of a specific hospital. In terms of Herzberg's theory, accepted as a framework for this study, factors can be intrinsic (motivating) or extrinsic (hygiene).

Motivation refers to a person's actions to fulfil specific needs. Motivation, as used in this study according to Herzberg's theory, comprises both extrinsic (hygiene) and intrinsic (motivating) factors.

A professional nurse, as used in this study, has undergone formal training and is registered with the Nursing and Midwifery Council (NMC) in the United Kingdom (UK), irrespective of the country where the nurse trained. A junior professional nurse is known as a staff nurse in the UK, the junior sister is the immediate supervisor of the staff nurse and the senior sister is usually the ward or unit manager in the UK (Lephalala, 2006:12).

Recruitment in this study refers to the attraction of new nurses, meeting specified needs, to join a specific institution's personnel.

Retention is the organisation's ability to retain employees' services for as long as possible. (High retention rates imply low turnover rates).

Turnover is the rate at which employees are replaced with new staff members in an organisation (Webster's Concise Edition Dictionary and Thesaurus, 2002:353). Involuntary turnover implies that the employee leaves the services of an organisation due to circumstances beyond the individual's control, such as family reasons, transfer of husband, ill health or reaching retirement age (Upenieks, 2005:22). Voluntary turnover refers to employees who leave an organisation based on their independent decisions to do so. Voluntary turnover can be influenced both by extrinsic (conditions surrounding the job also known as hygiene factors) and intrinsic (related directly to the job, also known as motivators) factors (Sullivan, Decker \& Jamerson, 2001:294). In this study the term tumover simply refers to the number of nurses who resign from the services of their employers.

Turnover rate is calculated by dividing the number of resignations by the number of nurses in a given period of time, usually a calendar year (Khowaja, Merchant \& Hirani, 2005:34).

\section{Purpose, Objectives and Assumptions of the study}

The purpose of this study was to identity factors influencing nurses' job satisfaction, and thus their turnover rates, in one group of private hospitals in England.

The objectives of the study were to

- obtain biographic information about the employed nurses and identify biographic factors which could influence nurses' job satisfaction and their potential turnover, such as age, qualifications, marital status, number of children

- identify extrinsic factors influencing no job satisfaction among nurses

- $\quad$ identify intrinsic factors influencing job satisfaction among nurses

- contribute to nursing as a profession by providing a basis for developing strategies to retain nurses in the private group of hospitals in England

The study was based on the following assumptions:

- Registered nurses' levels of job satisfaction influence turnover rates

- $\quad$ Registered nurses, working for the selected participating private hospitals in England, have good working conditions and enjoy high levels of job satisfcation.

- Hertzberg's Theory of

Motivation can be used to categorise the results of this study in terms of extrinsic (hygiene) and intrinsic (motivating) factors influencing nurses' levels of job satisfaction, and by implication their turnover rates.

\section{Literature Review}

The literature review will be presented according to the two factor theory of Herzberg, namely the intrinsic and extrinsic factors affecting nurses' job satisfaction.

\section{Extrinsic (hygiene) factors}

Extrinsic factors are also called hygiene factors and do not enhance an employee's level of job satisfaction, but reduce the level of no job satisfaction.

Group cohesion is "a staff member's perceptions of integration into the organisational and colleagial environment' (Shader, Broome, Broome, West \& Nash, 2001:213). The more the individual identifies with the group, the more the ability to conform to the group's norms and values. The group and the organisation become part of the individual and withdrawal from the organisation distorts the self-concept and seems like losing part of the self.

A study in Taiwan by Yin and Yang (2001:579), indicates that salary and fringe benefits were the strongest factors influencing nursing turnover. However, this does not necessarily imply that institutions with good salaries and attractive benefits have low staff turnover rates. A study done in Jordan (Mrrayan, 2005:47-48) indicates that nurses in private hospitals were more satisfied, and had higher intentions to stay, than nurses in public hospitals. Khowaja et al., (2005:34) cite Thomas' (1997) report about work stress in the NHS (UK) that had been aggravated by increased workloads, nursing shortages, job insecurities and organisational changes, influencing nurses' job satisfaction negatively. Upenieks (2005:24-25) cites Billingsley's (1999) report about the UK and Canada, experiencing the same problem of nursing shortage as the USA, where nurses' job vacancies were estimated to be $20 \%$ during 1999 . 
However, by 2020 the USA's projected shortage of nurses could reach 800000 , based on the employment of 3 million nurses during 2004 (Aiken, 2007:1300 citing the US Department of Health and Human services 2002). Thus the USA could exert strong pull factors on the global nurse supply, emphasising the importance that every country should promote its nurses' levels of job satisfaction, in order to retain its nurses' services within that specific country and/ or institution.

\section{Intrinsic factors (motivators)}

Intrinsic factors are motivators that relate to the person's job and promote his/her levels of satisfaction. In a study in the USA, Shader et al., (2001:214), found that work schedules was one factor that the institution could manipulate to enhance job satisfaction levels of nurses. Netswera, Rankhumise and Mavundla (2005:39) that South African institutions should help their employees to maintain a balance between their personal and work lives. One way of doing so is to provide timely information about work schedules. Strachota, Normandin, O'Brien, Clary and Krukow (2003:113), explained that age contributed to nurses' decisions of leaving an institution. Younger nurses still needed to explore fields other than nursing. Nurses in the older age bracket, intended staying with their employers until retirement, even if conditions were unfavourable. Autonomy and responsibility enhance nurse retention. The organisation that has autonomous and long-serving nurses, provide quality care to patients cost-effectively and this could further help to reduce turnover rates among nurses. Khowaja et al. (2005:34), indicated that nurses' lack of autonomy, inadequate staffing and work overload could affect their levels of job satisfaction, increasing turnover rates among nurses.

Tang (2003:9) indicates that nurses should be encouraged to participate in decision-making regarding the formulation of policies and the implementation of changes in a specific unit. If nurses realise that they are involved in decision-making processes, they might experience higher levels of job satisfaction and might stay longer in a specific organisation. Campbell, Fowles and Weber (2004:570) found that nurses needed more recognition to satisfy their needs for reputation, prestige and respect from others, which could lead to increased self esteem and job satisfaction. However, a lack of satisfaction of esteem needs leads to feelings of inferiority and discouragement, affecting job satisfaction negatively. In a study conducted in Finland, Kuokkanen and Leino-Kilpi (2001:278) found that empowered nurses were more skilled and competent. If the organisation does not provide a culture of recognition and promotion for employees, then workers might need to change jobs to procure some professional advancement. According to Yin and Yang (2001:580) nurse managers' position and power could influence nurses' intentions to stay. Nurse managers who encourage participation and who value contributions from staff, promote decision making and influence coordination, could enhance the positive aspects of a working environment that could help to maintain a stable nursing workforce, by reducing turnover rates.

\section{Research Method}

This study used a quantitative exploratory descriptive design to identify and describe factors that influence turnover among nurses in a private group of hospitals in England. Herzberg's Theory of Motivation was used as a conceptual framework for collecting and analysing data. The identified factors were categorised as extrinsic and intrinsic factors influencing nurses' job satisfaction, and by implication their intentions to leave or stay with the participating group of private hospitals in the UK.

\section{Population}

All nurses employed by the 21 hospitals of the participating private group of hospitals in England, at the time of the study (during January and February 2006), comprised the population of this study. It was impossible to include all 21 hospitals in the study due to time and financial constraints.

\section{Sample}

Simple random sampling was used in this study to select the participating five (out of a total of 21) hospitals, as each hospital had an equal and independent chance of being selected (Polit \& Hungler, 1999:284-286). The name of each of the 21 hospitals, in the participating private group of hospitals, was written on a slip of paper, folded and placed in a box. An independent person drew five pieces of paper (random sampling without replacement) from the box. The five hospitals' names on these slips of paper were the randomly selected hospitals participating in this study. Within each randomly selected hospital, all nurses registered with the NMC received questionnaires and no sample was drawn to select specific nurses. A total of 182 professional nurses worked at these five hospitals. Although 182 questionnaires were handed out, only 85 (46.7\% out of 182 ) usable completed questionnaires were returned. Thus the sample comprised these 85 completed questionnaires $(\mathrm{N}=85)$,

\section{Data collection}

Self-completion questionnaires were used to obtain data relevant to the study in order to answer the research questions. All 182 professional nurses employed by the five randomly selected hospitals during January and February 2006 , received questionnaires.

\section{Development of the questionnaire}

This study attempted to identify extrinsic and intrinsic factors influencing nurses' job satisfaction, in terms of Herzberg's Theory of Motivation. These factors were not specified as such in the questionnaire in order to avoid the possibility of creating mindsets in the respondents that were similar to these categories.

The questionnaire was discussed with two nurse researchers and a statistician. Most suggested changes pertained to rephrasing specific items so that each item had only one verb and addressed a single issue. The questionnaire comprised sections seeking information about:

- Demographic information such as age, gender, marital status, qualifications (11 items) as these aspects might impact on nurses' levels of job satisfaction Extrinsic factors that could influence nurses' levels of no job satisfaction (21 items)

- Intrinsic factors that could influence nurses' job satisfaction ( 20 items)

- Respondents' intentions to stay with or to leave the 
hospitals where they were employed at the time of completing the questionnaires (10 items), based on the assumption that satisfied nurses would remain while those not satisfied would consider leaving the organisation.

A pre-test was conducted with eight professional nurses working at one of the hospitals excluded from the actual study. Every nurse was also given a form to evaluate the questionnaire's clarity, appearance, layout, legibility, relevance, anonymity and privacy. No apparent problems were encountered during the pre-test phase with completing the questionnaires. The comments provided on the checklist indicated no further changes.

\section{Reliability and validity of the questionnaire}

Pre-testing of the questionnaire, involving eight registered nurses, produced similar results to those obtained during the actual data collection, indicating that the information remained reliable, amounting to testretest reliability.

In this study simple random sampling was used to select five out of 21 hospitals. This enhanced the external validity because the selected sample represented the population of 21 hospitals. However, all registered nurses employed by these five hospitals during January and February 2006 were requested to complete questionnaires, thus no sampling of individual nurses was done. In this study factors influencing nurses' job satisfaction were accepted to be a true reflection of reality, based on the literature review, evaluations by two nurse researchers and a statistician and by contextualising the data collection and analysis within Herzberg's theoretical constructs. Based on these inputs, the results of this study were accepted to be a true reflection of reality rather than the results of chance variables, amounting to internal validity (Burns \& Grove 2001:228).

\section{Ethical considerations}

Permission to conduct the study was sought from and granted by the healthcare authorities of the participating private group of hospitals in England. The matrons of the five participating hospitals were informed about the permission granted, and their permission was also requested. The matrons' co-operation was obtained to distribute the questionnaires to all registered nurses working at the participating hospitals.

In this study there was no physical harm anticipated from the completion of questionnaires distributed by the matrons of the five participating hospitals. Every questionnaire was sealed in an envelope with a pen, a stamped addressed envelope, and a leaflet with information about the research project. The information leaflet explained that participation was voluntary and depended on the discretion of every individual; requested that completed questionnaires be posted within two weeks; assured respondents that all data would be treated in a confidential and anonymous manner and that no nurses' or hospitals' names would be mentioned in the research report. The researcher's telephone number was supplied in case more information was desired. No consent form was included (to ensure the anonymity of each participant) but completion and return of the questionnaire implied consent.

\section{Analysis and Discussion of Data}

Data analysis commenced after no further completed questionnaires had been received for three successive weeks - by the end of March 2006. The total number of questionnaires used in the data analysis was 85 , but not all totals add up to 85 as some respondents failed to complete specific items. Data from the questionnaires were statistically analysed using the Microsoft Excel computer program. Please note not all respondents answered every question, consequently the total number of responses to specific items vary and does not always add up to 85 in tables 3 and 4 . The percentages were calculated based on the number of responses to individual items.

\section{Biographic data}

Items in the questionnaire attempted to obtain information about the respondents' ages, gender, marital status, number of dependants, monthly incomes and years' of experience with the specific hospital. The assumption was that biographic factors might impact on intrinsic and extrinsic factors influencing nurses' job satisfaction.

Of the 85 respondents, $32.94 \%(n=28)$ fell within the age group of 50 years of age or older. Respondents aged between 40 and 49 years were $37.65 \%(n=32)$. Only $3.53 \%(n=3)$ RNs' ages ranged from 26 to 30 years while $22(25.88 \%)$ fell within the age group of 31 to 39 . This implies that $70.59 \%(n=60)$ of the respondents were 40 years of age or older, who could retire from active nursing service with the next 20 years, but $32.94 \%(n=28)$ might retire within the next 5-10 years as they were 50 years of age or older. The nurses' ages could influence the expected rate of turnover in the participating group of private hospitals in England within the foreseeable future. However, Strachota et al. (2003:13) maintain that older nurses are likely to stay with their institutions

Table 2 Respondents' years of experience $(n=85)$

\begin{tabular}{|l|l|l|l|l|}
\hline \multirow{2}{*}{ Years of Experience } & \multicolumn{2}{|c|}{ After basic training } & \multicolumn{2}{c|}{ With current employer } \\
\hline & Frequency & $\%$ & Frequency & $\%$ \\
\hline $0-5$ & 2 & $2.35 \%$ & 38 & $44.71 \%$ \\
\hline $6-10$ & 5 & $5.88 \%$ & 19 & $22.35 \%$ \\
\hline $11-15$ & 13 & $15.29 \%$ & 10 & $11.76 \%$ \\
\hline $16-20$ & 15 & $17.65 \%$ & 11 & $12.94 \%$ \\
\hline $20+$ & 50 & $58.82 \%$ & 7 & $8.24 \%$ \\
\hline Total & 85 & $99.99 \%$ & 85 & $100.00 \%$ \\
\hline
\end{tabular}


Table 3: Extrinsic (hygiene) factors influencing nurses' levels of no job satisfaction

\begin{tabular}{|c|c|c|}
\hline No satisfaction & & Satisfaction \\
\hline & $\begin{array}{l}\text { EXTRINSIC (HYGIENE) FACTORS } \\
\text { Working conditions }\end{array}$ & \\
\hline$(40.51 \%)$ & Respect from management & $(59.5 \%)$ \\
\hline \multirow[t]{2}{*}{$(39.51 \%)$} & Communication among team members & $(60.49 \%)$ \\
\hline & Salary & $\cdot$ \\
\hline$(67.53 \%)$ & $\begin{array}{l}\text { Would leave hospital for better remuneration } \\
\text { Not fairly rewarded considering } \\
\text { responsibilities compared to:- }\end{array}$ & $(32.46 \%)$ \\
\hline$(55.56 \%)$ & Nurses working for the NHS & $(44.44 \%)$ \\
\hline$(42.31 \%)$ & Nurses in other private hospitals in the UK & $(51.22 \%)$ \\
\hline \multirow[t]{2}{*}{$(46.25 \%)$} & Nurses in the same hospital & $(53.75 \%)$ \\
\hline & Organisation and administration policies & \\
\hline$(13.42 \%)$ & Receive updates on equipment & $(86.58 \%)$ \\
\hline$(9.76 \%)$ & $\begin{array}{l}\text { Understand standard operating procedures } \\
\text { Know where to access information }\end{array}$ & $(90.24 \%)$ \\
\hline$(4.94 \%)$ & regarding:- & $(95.06 \%)$ \\
\hline \multirow[t]{2}{*}{$(12.35 \%)$} & $\begin{array}{l}\text { Patient care } \\
\text { Unit management }\end{array}$ & $(87.65 \%)$ \\
\hline & Supervision & \\
\hline$(21.43 \%)$ & Support provided to subordinates & $(78.57 \%)$ \\
\hline$(10.84 \%)$ & Feedback given & $(89.17 \%)$ \\
\hline \multirow[t]{2}{*}{$(25.0 \%)$} & Regular performance appraisals & $(75.0 \%)$ \\
\hline & Interpersonal relations & \\
\hline$(29.27 \%)$ & Group cohesion & $(70.73 \%)$ \\
\hline$(28.05 \%)$ & Social relations with peers & $(71.95 \%)$ \\
\hline$(20.73 \%)$ & Working with people they trust & $(79.27 \%)$ \\
\hline
\end{tabular}

till retirement, even if their job situations are unfavourable, while younger nurses are likely to explore other possibilities.

Out of the $85 \mathrm{RNs}, 75.29 \%(\mathrm{n}=64)$ were reportedly married. According to (Mrayyan, 2005:47) more nurses working in private hospitals tended to be married than nurses working in public hospitals. The majority of the respondents were females $(\mathrm{n}=78,92.86 \%)$. This finding correlates with the NMC's (2004) statistics indicating that $89.79 \%$ of the nurses on their register were females and $10.21 \%$ were males.

Of the $79 \mathrm{RNs}$ who responded to this question, $46.84 \%(n=37)$ had achieved diplomas, $6.33 \%(n=5)$ had bachelor's degrees and $1.27 \%(n=1)$ had master's degrees. Of the respondents $32.10 \%$ $(n=26)$ had no children, $25.93 \%(n=21)$ had one child, $27.16 \%(\mathrm{n}=22)$ had two children and $14.81 \%(\mathrm{n}=12)$ had three children, implying that $67.90 \%(n=55)$ of the respondents had children.

Of the $83 \mathrm{RNs}, 16.87 \%(\mathrm{n}=14)$ received up to $£ 999$, those who received $£ 1000$ to $£ 1499$ were $38.55 \%(n=32)$, whereas $31.33 \%(n=26)$ received from $£ 1500$ to $£ 1999$ and $13.25 \%(n=11)$ received more than $£ 2000$ per month. Out of the 85 respondents, $45.88 \%(n=39)$ worked 5 days per week and the majority of RNs, $71.76 \%(n=61)$ worked 7.5 hours per day.

Table 1 illustrates the years of experience of the respondents and the years with the present organisation.

As many as $44.71 \%(n=38)$ of the respondents reportedly had five years or less experience with their current hospitlas, implying that $44.7 \%$ of the five participating hospitals' nurses had been appointed during the preceding five years (2001-2006). This amounts to an average of $8.9 \%$ newly appointed registered nurses per annum, indicating a low turnover rate among registered nurses in these five hospitals.

Of the 85 RNs, $52.94 \%(n=45)$ were staff nurses, $17.65 \% \quad(n=15)$ were senior staff nurses, $3.53 \%(\mathrm{n}=3)$ were junior sisters, $22.35 \%(n=19)$ were senior sisters and $3.75 \%(\mathrm{n}=3)$ failed to indicate their ranks. Out of the 84 respondents, $67.86 \% \quad(\mathrm{n}=57)$ perceived that the units where they were working, were adequately staffed but $32.14 \%(n=27)$ indicated that nursing shortages existed in their units. Perceived nursing shortages impact negatively on nurses' job satisfaction and might influence their decisions to leave the services of their current employers (Khowaja et al., 2005:34; Upenieks, 2005:24-25).

These findings indicate that the majority of the respondents were female, married and had dependants, implying that they had to combine their nursing responsibilities with those of being mothers and wives. It is thus possible that their job satisfaction levels would be influenced by the perceived abilities to combine their nursing roles with those of being mothers and wives.

\section{- Extrinsic (hygiene) \\ factors influencing turnover}

The extrinsic (hygiene) factors influencing turnover that were investigated included working conditions, organisation and policy organisation, group cohesion, supervision and salaries. Extrinsic (hygiene) factors emphasise aspects contributing to no satisfaction, in terms of Herzberg's Theory of Motivation.

\section{Working conditions}

As indicated in table $3,40.51 \%(n=32)$ of the respondents reported no satisfaction with respect shown by management and $31.59 \%(n=32)$ reported no satisfaction with communication among members of the multidisciplinary team. However, more than half of the respondents reported satisfaction with both management's respect and multidisciplinary team members' communication.

\section{Salary}

As many as $67.53 \%(n=52)$ indicated that 
they would leave their current hospitals for better remuneration, implying that they had no satisfaction about their salaries, when comparing their responsibilities to those of nurses working in other private hospitals $(42.31 \% ; n=33)$ or in the NHS $(55.56 \%$; $\mathrm{n}=45$ ). A similar trend was noticed when comparing the respondents' salaries, considering their qualifications, with those of nurses in the NHS because $56.79 \%(\mathrm{n}=46)$ had no satisfaction in this regard: nor were $48.79 \%(n=40)$ satisfied about their salaries compared to those of nurses in other private hospitals. Even $46.25 \%(n=37)$ of the participants reported no satisfaction when comparing their salaries and qualification to those of other nurses employed by the same hospital. Yin and Yan (2001:579) maintain that salary and fringe benefits are strong factors influencing nurses' turnover rates.

\section{Organisation and policy administration}

As many as $90.24 \%(\mathrm{n}=74)$ and $86.58 \% \quad(n=71)$ were satisfied with regard to the standard of operating procedures and receiving updates about equipment respectively. Almost all respondents knew where to access information regarding unit management $(87.65 \% ; n=74)$ and patient care $(95.06 \% ; n=81)$.

\section{Supervision}

However, the majority of respondents indicated satisfaction with their supervisors' feedback $(89.16 \% ; n=74)$; support $(78.57 \% ; \mathrm{n}=66)$ and performance appraisals $(75.0 \% ; n=64)$. Thus those who reported no satisfaction with these aspects of supervision were in the minority ranging from $10.84 \%$ to $25.0 \%$.

\section{Group cohesion}

The majority of respondents indicated satisfaction in relation to interpersonal relations. As many as $79.27 \%(n=65)$ trusted the people with whom they worked, $71.95 \% \quad(n=59)$ were satisfied with social relations with their peers and $70.73 \%(n=58)$ were satisfied with their perceived levels of group cohesion. The respondents who reported no satisfaction about aspects relating to interpersonal aspects were in the minority, ranging from $20.73 \%$ to $29.27 \%$. Shader et al. $(2001: 213)$ maintain that individuals who identify with their colleagues and work environment are better able to conform to the group's norms and values.

\section{- Intrinsic factors influencing turnover}

The intrinsic factors that will be discussed in this section include the work itself, recognition, achievement, advancement and responsibility, as summarised in table 4.

\section{Achievements}

Only $9.09 \%(n=7)$ of the respondents were satisfied with promotions but the majority $(90.91 \% ; n=70)$ were not satisfied. Only $65.43 \%(n=53)$ of the respondents were satisfied that qualifications were considered for promotions, while $56.25 \%(n=45)$ were satisfied that experience was a major consideration during promotions. These findings indicate registered nurses' lack of satisfaction with the regularity of promotions and, to a lesser extent, the importance of qualifications and experience for getting promoted.

\section{Recognition}

Of the respondents, $83.95 \% \quad(n=68)$ indicated satisfaction because their opinions were valued by medical staff and that senior nurses received more recognition than junior nurses $(66.27 \%$; $\mathrm{n}=55)$. However, only $54.22 \%(\mathrm{n}=46)$ indicated that they were satisfied with the recognition of additional qualifications, while $45.79 \% \quad(n=38)$ reported no satisfaction about this issue.

\section{Responsibility}

As many as $71.79 \%(n=56)$ of the respondents reported satisfaction with professional autonomy. However, $50.62 \%(n=41)$ and $47.56 \%(n=39)$ were not satisfied with their involvement in policy making and decision making processes respectively. Yin and Yan (2001:580) maintain that nurse managers who manage to involve nurses in

\section{Table 4: Intrinsic (motivating) factors influencing nurses' job satisfaction}

\section{MOTIVATORS INFLUENCING NURSES JOB DISSATISFACTION}

No satisfaction

Satisfaction

\section{INTRINSIC FACTORS (MOTIVATORS)} Achievements
$(90.91 \%)$

$(43.75 \%)$

$(34.56 \%)$

$(45.79 \%)$

$(33.74 \%)$

(16.05\%)

$(50.62 \%)$

(47.56\%)

$(28.21 \%)$

$(48.19 \%)$

$(55.56 \%)$

$(34.18 \%)$

(29.63\%)

$(34.52 \%)$

$(59.76 \%)$

$(46.76 \%)$
Promotions are regular

Only experience is mostly considered for promotions

Qualifications not considered for promotion

\section{Recognition}

Additional qualifications not recognised

More recognition of senior nurses

Nurses' opinions valued by medical staff

$(54.22 \%)$

$(66.27 \%)$

$(83.95 \%)$

\section{Responsibility}

Involvement during policy making

Involvement during decision making

Professional autonomy

\section{Nature of work itself} Workloads

Disruptions in social life due to working hours

Work schedules

Not paid for overtime but claiming hours

Sufficient time to get everything done

$(70.37 \%)$

$(65.48 \%)$

\section{Advancement}

Advancement opportunities

$(40.25 \%)$

Being in a dead-end job 
decision-making and policy-making activities, enhance the positive nature of the work environment and thereby nurses' job satisfaction.

\section{Nature of work itself}

As many as $55.56 \% \quad(n=45)$ of the respondents indicated that they were not satisfied with social disruptions caused in their lives by their working schedules. As many as $70.37 \%(n=57)$ were satisfied with working overtime without compensation, but being granted the overtime hours at times deemed suitable by the hospital. This finding seems to contradict that of Schader et al. (2001:215) who maintain that this situation makes it hard for nurses to plan their personal and family lives without financial compensation, leading to higher turnover rates. Only $34.52 \%(n=29)$ were not satisfied with the sufficiency of the time to get their jobs done.

\section{Advancement}

As many as $59.49 \%$ (49) of the respondents indicated no satisfaction because of lack of advancement opportunities and $46.76 \%$ (36) perceived themselves to be in deadend jobs.

\section{Conclusions}

In relation to the assumptions underlying the study, the major conclusions can be rephrased to state that intrinsic and extrinsic factors influenced nurses' levels of job satisfaction (as summarised in Tables 3 and 4).

Hygiene factors reduced the level of dissatisfaction, namely, working conditions, supervision, organisation and administration policies, supervision and group cohesion. The highest percentage of no satisfaction was accorded to salary, as $67.53 \%(n=52)$ of the respondents indicated that they would leave their hospitals for better remuneration. The respondents were not satisfied with their salaries when considering their responsibilities and qualifications compared to those of nurses working in other private hospitals, the NHS or even in their own hospitals. Other extrinsic (hygiene) factors with which some respondents reported no satisfaction include respect shown by management and communication among multidisciplinary team members. However, most of the participating nurses (ranging from $70.73 \%$ to $89.17 \%$ ) were satisfied with extrinsic (hygiene) factors related to organisation and administration policies, supervision and interpersonal relations.

The issue of promotions was the major intrinsic factor that impacted negatively on job satisfaction among registered nurses working at the participating private hospitals in England. Almost all nurses $(90.0 \% ; \mathrm{n}=70)$ reported no satisfaction with regular promotions, nor with the importance accorded to experience versus qualifications during promotions. This finding seems to correlate with $69.76 \%(n=49)$ who reported no satisfaction with advancement opportunities and $46.76 \%$ $(\mathrm{n}=36)$ who reported no satisfaction about being in a dead-end job. Although the majority of the participating nurses $(71.79 \% ; n=56)$ reported satisfaction with their professional autonomy, far fewer were satisfied with their participation in policy making $49.38 \%(n=40)$ and in decision making $52.43 \%(n=43)$. The nurses reported satisfaction about the other motivating (intrinsic) factors namely, the nature of the work itself and recognition.

\section{Limitations}

The following limitations, could limit the generalisability of the research results.

- $\quad$ No literature was available on factors influencing nurses' turnover rates in the selected private hospitals in England. Thus the researchers had no data for comparison.

- $\quad$ Some respondents might have misinterpreted some questionnaire items. This limitation might have been addressed by conducting interviews, but this was impossible due to the time limitations, issues of anonymity (and possibly confidentiality) and geographical distances to reach the participating hospitals.

- Only professional nurses participated in this study. Consequently, the results may not be generalisable to other categories of nurses working within the participating group of private hospitals.

- Different results might have been obtained if nurses who had actually resigned from working at the participating hospitals had completed the questionnaires (but no census of resigned nurses could be traced). In this case the intrinsic and extrinsic factors influencing nurses' job satisfaction could have been compared between the two groups: those still employed by and those having resigned from the hospital concerned.

- $\quad$ There might be other factors influencing registered nurses' job satisfaction that remained unidentified in this quantitative exploratory survey. Such factors could be identified in future research projects utilising in-depth qualitative interviews.

\section{Recommendations}

Recommendations, based on the conclusions, address ways in which nurses' job satisfaction could be enhanced (and turnover rates reduced) in the participating group of private hospitals in England.

- The most important issue to be addressed is that of promotions. The regularity of promotions, and considerations of experience, qualifications and the attainment of additional qualifications, should be specified and communicated to all registered nurses.

- $\quad$ The participating private group of hospitals should compare the salaries paid to registered nurses to those of nurses working in other private hospitals and in the NHS, considering the nurses' responsibilities and qualifications. The situation where nurses within the same hospital reportedly received different salaries for comparable responsibilities, experiences and qualifications should be investigated and addressed.

- Clearly formulated promotion policies, and salary scales for different registered nurses' ranks, should be available to all registered nurses within the private group of hospitals. This could reduce confusion and the levels of no satisfaction with the 
most important extrinsic (salary) and intrinsic (promotion) factors influencing nurses' levels of job satisfaction.

- Ways should be found in which communication among multidisciplinary team members and respect shown to registered nurses by management could be improved.

- $\quad$ Registered nurses should be formally involved in decision making and policy making processes so that they feel part of these processes.

- Work schedules should be available in good time; be as flexible as possible and minimal changes (with consultation of all concerned) should be implemented in order to avoid disrupting nurses' social lives and family commitments.

- During performance appraisals, supervisors should address issues like, promotions, salaries, advancement opportunities, recognition, responsibility and achievements in order to address feelings of being in dead-end jobs.

- $\quad$ Registered nurses' supervisors at the participating five hospitals need to be congratulated because most nurses (ranging from $70.73 \%$ to $90.24 \%$ as indicated in table 3 ) reported satisfaction with organisation and administration policies, supervision and maintaining interpersonal relations.

"Nursing ... is evolving at a rapid pace not only in its practice domain, but also in its role within the health care delivery, system, locally, nationally and internationally" (Reilly \& Oermann 1999:ix). Unless sufficient numbers of nurses are recruited and retained within the nursing profession, the health care clients might not receive the type of health care they are entitled to. The need to reduce turnover rates among nurses in the UK remains paramount, considering that the UK recruited 57136 nurses from non-European countries from 1998 till 2003 (Lephalala 2006:3) Addressing both intrinsic and extrinsic factors (in terms of Herzberg's Theory) might contribute to enhancing registered nurses' job satisfaction reducing turnover rates among nurses in the participating private group of hospitals in England.

\section{References}

AIKEN, LH 2007: U.S. nurse labor market dynamics are key to global nurse sufficiency. Health Services Research. 42(3):1299-1320

AIKEN, LH; BUCHAN, J; SOCHAISKI, , BN \& POWELL, M 2004: Trends in international nurse migration. Health Affairs, 23(3):69-77.

BALL, J 2003: Understanding Herzberg's motivation theory. http:// www.accaglobal.com/publications/ $\underline{\text { studentaccountant/1010721 accessed }}$ 17 May 2005).

BUCHAN, J 2004: Commentary. Nurse workforce planning in the UK: policies and impact. Journal of Nursing Management. 12: 388-392.

BUCHAN, J 2007: International recruitment of nurses: policy and practice in the United Kingdom. Health Services Research, 42(3): 1321-1335.

\section{BRITISH POPULATION STATISTICS} 2003: (http://www.woodlandsiunior.kent.sch.uk/customs/questions/ population.html accessed on 03 June 2005).

BURNS, N \& GROVE, SK 2001: The practice of nursing research: conduct, critique, and utilization. $4^{\text {th }}$ edition. Philadelphia: WB Saunders

CAMPBELL, SL; FOWLES, ER \& WEBER, BJ 2004: Organisational structure and job satisfaction in public health nursing. Public Health Nursing. 21(6): 564-571.

COWIN, 2002: The effects of nurses' job satisfaction on retention: an Australian perspective. Journal of Nursing Administration, 32(5):283-291.

DAFT, RL 2000: Management. $5^{\text {th }}$ edition. New York: The Dryden Press.

KHOWAJA, K; MERCHANT, RJ \& HIRANI, D 2005: Registered nurses' perception of work satisfaction at a tertiary care university hospital. Journal of Nursing Management. 13 (1): 32-39.
KINGMA, M 2007: Nurses on the move: a global overview. Health Services Research, 42(3): 1281-1298.

KUOKKANEN, L \& LEINO-KILPI, H 2001: The qualities of an empowered nurse and the factors involved. Journal of Nursing Management. 9:273-280.

LEPHALALA, RP 2006: Factors influencing nursing turnover in selected private hospitals in England. Unpublished MA Cur dissertation. Pretoria: University of South Africa.

MARQUIS, BL \& HUSTON, JC 2003: Leadership roles and management functions in nursing theory \& application. $4^{\text {th }}$ edition. Philadelphia: JB Lippincott.

MRAYYAN, MT 2005: Nurse job satisfaction and retention: comparing public to private hospitals in Jordan. Journal of Nursing Management. 13(1): $40-50$.

NETSWERA, FG; RANKHUMISE, EM \& MAVUNDLA, TR 2005: Employee retention factors for South African higher education institutions: A case study. SA Journal of Human Resource Management. 3(2): 36-40.

NMC - see NURSING AND MIDWIFERY COUNCIL

NURSING AND MIDWIFERY COUNCIL 2004: Press statement: record of overseas trained nurses and midwives ht t p://www.nmc-uk.org/ aFrameDisplav.aspx?documentID $=197$ (accessed 30 May 2006).

POLIT, DF \& HUNGLER, BP 1999: Nursing research: principles and methods. $6^{\text {th }}$ edition. Philadelphia: JB Lippincott.

REILLY, DE \& OERMANN, MH 1999: Clinical teaching in nursing education. $2^{\text {nd }}$ edition. Sudbury: Jones \& Bartlett.

SHADER, K; BROOME, ME; BROOME, CD; WEST, ME \& NASH, M 2001: Factors influencing satisfaction and anticipated turnover for nurses in an academic medical center. Journal of Advanced Nursing. (4): 210-216.

STRACHOTA, E; NORMANDIN, P; O'BRIEN，N; CLARY， NA \& 
KRUKOW, B 2003: Reasons registered nurses leave or change employment status. Journal of Nursing Administration. 33(2): 111-117.

SULLIVAN, EJ; DECKER, PJ \& JAMERSON, PA 2001: Effective leadership and management in nursing. $5^{\text {th }}$ edition. New Jersey: Prentice-Hall.

TANG, JH 2003: Evidence-based protocol: nurse retention. Journal of Gerontological Nursing. 29 (3): 5-14.

UPENIEKS, V 2005: Recruitment and retentions strategies: a magnet hospital prevention model. MEDSURG Nursing (supplement). 21-27.

WEBSTER'S CONCISE EDITION DICTIONARY AND THESAURUS 2002:

Edinburgh: Geddes \& Grosset.

YIN, JT \& YANG, KA 2002: Nursing turnover in Taiwan: a meta-analysis of related factors. International Journal of Nursing Studies. 39: 573-581. 